\title{
Correction to: How are the village health volunteers delivering malaria testing and treatment services and what are the challenges they are facing? A mixed methods study in Myanmar
}

Nay Yi Yi Linn ${ }^{1 *}$, Jaya Prasad Tripathy ${ }^{2,3}$, Thae Maung Maung ${ }^{4}$, Khine Khine Saw ${ }^{1}$, Lei Yee Win Maw ${ }^{5}$, Badri Thapa ${ }^{6}$, Zaw Lin' ${ }^{1}$ and Aung Thi ${ }^{1}$

\section{Correction}

In the original publication of this article [1], the article title should be changed to "How are the village health volunteers delivering malaria testing and treatment services and what are the challenges they are facing? A mixed methods study in Myanmar".

\section{Author details \\ ${ }^{1}$ Vector Borne Disease Control Program, Ministry of Health and Sports, Nay Pyi Taw, Myanmar. ${ }^{2}$ International Union Against Tuberculosis and Lung Disease, The Union South East Asia Office, New Delhi, India. International Union Against Tuberculosis and Lung Disease, Paris, France. ${ }^{4}$ Department of Medical Research, Ministry of Health and Sports, Yangon, Myanmar. \\ ${ }^{5}$ Independent Public Health Consultant, Yangon, Myanmar. ${ }^{6}$ Malaria Unit, \\ World Health Organization Country Office, Yangon, Myanmar.}

Published online: 07 November 2018

\section{Reference}

1. Linn NYY, et al. How are the village health volunteers delivering malaria

testing and treatment services and what are the challenges they are facing?

A mixed methods study in Myanmar. Trop Med Health. 2018;46:28

https://doi.org/10.1186/s41182-018-0110-0.

\footnotetext{
* Correspondence: nayyiyilinn@gmail.com

'Vector Borne Disease Control Program, Ministry of Health and Sports, Nay

Pyi Taw, Myanmar
} 